\title{
The influence of the opening width of check dams on bedload continuity of mountain rivers
}

\author{
S. Schwindt, M.J. Franca \& A.J. Schleiss \\ Laboratoire de constructions hydrauliques, École Polytechnique Fédérale de Lausanne, Lausanne, Switzerland
}

\begin{abstract}
The design of open check dams at mountain rivers for flood protection has an essential impact on the sediment budget of downstream river reaches. A key issue is the bedload transfer hindering and retention which can be influenced by the geometry of the openings of check dams. Contemporary design concepts provoke the retention of too much or insufficient bedload with regard to the downstream transport capacity. This dysfunction can cause continuous maintenance works or endanger downstream infrastructures, respectively. Herein an experimental analysis of the influence of check dam openings on the bedload transport capacity is made as a function of the constriction ratio of the opening width and the mean width of the undisturbed channel. Constriction ratios of more than 0.9 have no significant influence on the bedload transport capacity, while constriction ratios of less than about 1/3 block every grain larger than $1 / 40$ of the channel width.
\end{abstract}

\section{INTRODUCTION}

The space for settlement area and infrastructures in mountainous regions is confined by the steep topography of the alpine terrain and the risk of natural disasters. The surplus of sediment due to high supply in upstream reaches is often exploited by gravel extraction or retained by check dams. Former river training works aimed only directly at the protection of infrastructures and dwellers or the maximization of land availability for agriculture, industry and settlement purposes. However, the sediment retention in upstream river reaches is a severe problem and often requires sediment replenishment in downstream river reaches to prevent channel incision (Kondolf 1997, Williams \& Wolman 1984). The alpine rivers Thur and Emme in Switzerland have been subjected to river training works and gravel extraction in the middle of the 20th century. Nowadays countermeasures are undertaken to reestablish a naturallike sediment transport and to prevent gradual erosion effects which occurred due to the former measures (Hunziker 2012).

An improvement of the situation can be achieved by the implementation of open check dams. The openings in check dams are intended to allow for sediment transport up to a certain design discharge which has to be determined individually for every project. Thus, the objective of open check dams is to retain sediments only partially, i.e. during high floods. However, the contemporary design of the open type of check dams often retains too much sediment and regular maintenance works in terms of reservoir dredging are required to prevent progressive backfilling. In this case, the longitudinal river connectivity is still interrupted in terms of eco-morphologic aspects like the migration of aquatic organisms and the substrate availability in the form of sediment transported by the river. Accordingly, an adequate design of open check dams is crucial for reducing the human impact on the sediment budget of the whole river which manifests impressively at marine estuaries like described by Syvitski et al. (2012).

Despite the need for sediment continuity, check dam openings also have an upper size limit which is imposed by safety aspects. It is necessary to retain the part of the sediment supply which exceeds the downstream bedload transport capacity at critical points, like the passage of settlements during floods.

Therefore, check dam openings should be sufficiently wide for ensuring the longitudinal connectivity in terms of sediments but still keep their role of protecting downstream infrastructures in case of floods.

Open check dams can be clogged by two different mechanisms: (i) mechanically, i.e. when obstacles which are larger than the opening are transported by the river or (ii) hydraulically, i.e. when the discharge capacity of the opening is exceeded (Piton \& Recking 2015). This study focusses on the bedload retention due to hydraulic obstruction, where bedload is intended to pass undisturbed most of the time. The bedload transfer capacity 


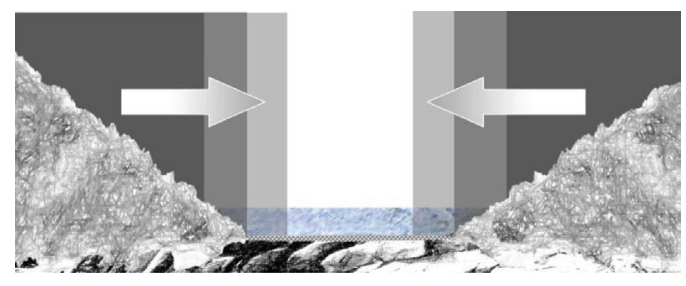

Figure 1. Illustration of the narrowing of river constrictions imposed by open check dam with an open crest.

of open check dams has only partially been examined, e.g. by Armanini \& Larcher (2001) for large and narrow slits with an open dam crest. A missing link is the understanding of the influence of the ratio between the width of flow constrictions and the natural river width on the bedload transport capacity. This study investigates experimentally the influence of the width of flow constrictions of check dam openings on the bedload transport capacity of mountain rivers (Fig. 1).

\section{METHODOLOGY}

\subsection{Experimental setup}

The main channel of the experimental setup is about $3.0 \mathrm{~m}$ long, with a longitudinal slope of about $2 \%$ and has a rough fix bed which is composed by the coarse fraction of the bedload supply (Schwindt et al., 2015). The trapezoidal channel has a base width of about $0.15 \mathrm{~m}$ and a bank slope of about $30^{\circ}$. An upstream mixing channel, which is about $2.5 \mathrm{~m}$ long, serves to establish the adequate boundary conditions in terms of fully established and equally distributed bedload transport at the model entrance. The channel cross section and the derivation of the mean flow width $w$ are described in Figure 2.

Sediments are supplied by a conic container with a perforated screw on the bottom, which also defines the sediment supply rate by its driving speed. The grain size distribution of the feeding mixture is characterized by $\mathrm{D}_{30}=4.1 \mathrm{~mm}, \mathrm{D}_{50}=5.3 \mathrm{~mm}$, $\mathrm{D}_{\mathrm{m}}=8 \mathrm{~mm}, \mathrm{D}_{90}=14 \mathrm{~mm}$ and $\mathrm{D}_{\max }=21 \mathrm{~mm}$. The wetted sediment mixture is transferred by a system of conveyor belts in the upstream mixing channel and weighted at the model outlet by means of a suspended filter basket. The pump discharges vary between 5.5 and $9.5 \mathrm{l} / \mathrm{s}$.

The measuring equipment consists of ultrasonic probes for the derivation of the water surface level and water depth, a flowmeter for flow velocity measurements and several cameras for the observation of sediment depositions. The sediment input and output are evaluated by the weighting

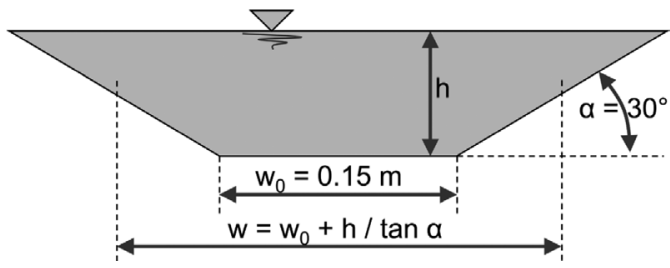

Figure 2. Geometry of the flow cross section of the laboratory flume.

continuously the filter baskets at the model downstream section by means of an industrial scale.

The open check dam is positioned $0.8 \mathrm{~m}$ upstream of the channel outlet and constructed by means of adaptable, mobile PVC elements like illustrated in Figure 3.

\subsection{Experimental procedure}

The maximum bedload transfer rate $Q_{b, \max }$, i.e. the maximum sediment supply rate at which the grains do not deposit in the undisturbed channel, is investigated incrementally for the range of the pump discharge with a step size of $0.5 \mathrm{l} / \mathrm{s}$ in the range between $5.5 \mathrm{l} / \mathrm{s}$ and $9.5 \mathrm{l} / \mathrm{s}$. The investigation of $Q_{b, \max , i}$ starts with the injection of sediment equivalent to $50 \%$ of the computed bedload capacity established theoretically by means of the Smart \& Jaeggi formula (Smart \& Jaeggi 1983). Subsequently, the supply rate is incrementally increased until the first deposits of sediments in the channel bed are observed. The relation between water discharge and maximum sediment discharge $Q_{b, \max , i}$ is obtained by applying the maximum sediment discharge rate which does not cause deposition.

The calibration procedure is illustrated Figure 4 for the pump discharge of $8.9 \mathrm{l} / \mathrm{s}$. Following the graph, it can be observed that with increasing sediment injection rate, also the sediment output rate increases, until a maximum value is reached. This maximum value defines the maximum bedload transport rate of the flume which for the pump discharge of $8.9 \mathrm{l} / \mathrm{s}$ is $Q_{b, \max , 1} \approx 0.03 \mathrm{~kg} / \mathrm{s}$.

First this procedure is accomplished for the undisturbed channel. Then the PVC elements are introduced laterally for reproducing the flow constriction imposed by open check dams. The channel constrictions are expressed by means of the constriction ratio $\varphi$ of the constriction, defined as the ratio between the width $b$ and the mean width $w$ of the undisturbed flow.

Thus, for the lateral constrictions, the maximum bedload transfer rate $Q_{b, \max , \varphi}$ is derived as well according to the same procedure as for the undisturbed channel. 


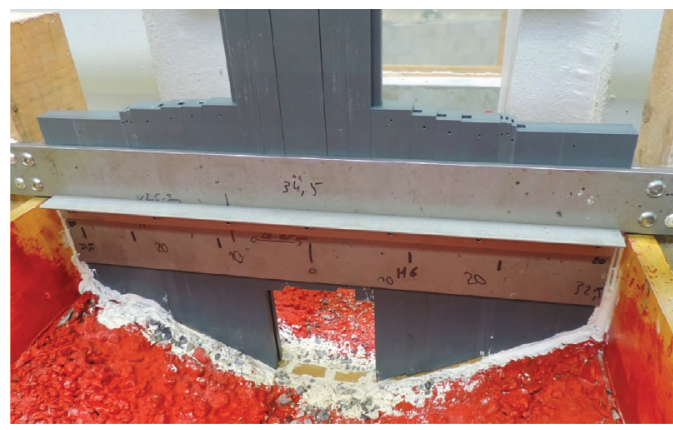

Figure 3. Laboratory flume with PVC elements for constricting the flow laterally.

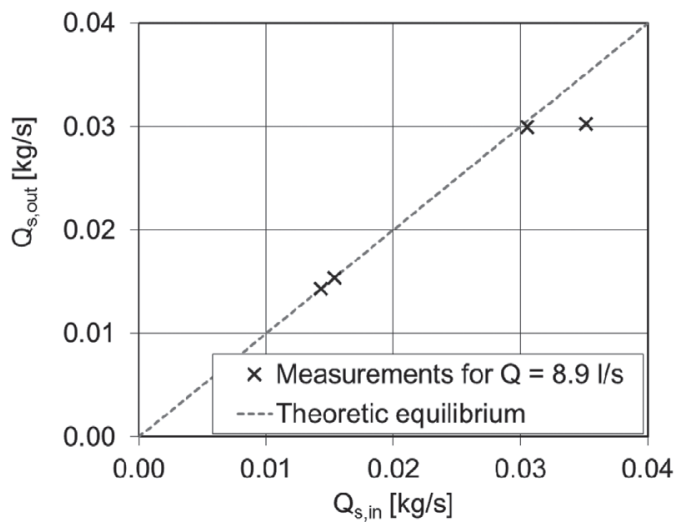

Figure 4. Illustration of the procedure to define the maximum solid discharge corresponding to a pump discharge of $8.9 \mathrm{l} / \mathrm{s}$ which is completely transported without causing deposition in the bed channel-the injection of solid discharges is increased until depositions in the flume occur and the maximum bedload transport rate is observed here with about $0.03 \mathrm{~kg} / \mathrm{s}$.

\subsection{Parameters}

The reference values and the constriction values which are compared are the bedload transport capacity $Q_{b \text { max. }}$ of the undisturbed channel (reference) and bedload transport capacity $Q_{b, \max , \varphi}$ of the constricted channel. The ratio of the maximum sediment transport rate $Q_{b, \max , \varphi}$ for every constriction value $\varphi=b / w$ and the maximum transport rate of the undisturbed flow $Q_{b, \max , 1}$ is expressed by transport capacity reduction ratio $\theta$ :

$\theta=\frac{Q_{b, \max , \varphi}}{Q_{b, \max , 1}}=f(\varphi)$

The theoretical mean width $w$ of the undisturbed channel as shown in Figure 2 is interpolated

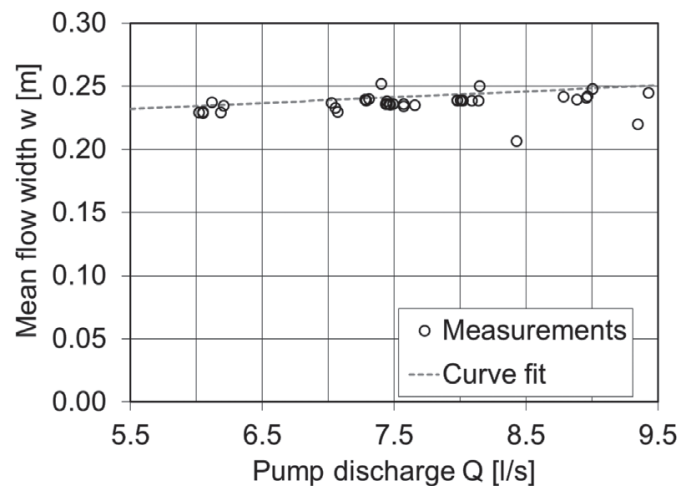

Figure 5. Evaluation of the mean flow width as a function of pump discharges.

by a linear function of the pump discharges $Q$ as illustrated in Figure 5.

Thus, the theoretical mean width of the undisturbed channel can be computed based on the pump discharge as follows:

$w(Q)=0.047 \cdot Q+0.206$

\section{RESULTS}

\subsection{Maximum bedload transport}

As stated above, the bed load transport capacity corresponds to the maximum bedload transport in the channel without the occurrence of depositions. A comparison of the maximum bedload transport in the undisturbed channel $Q_{b, \max , 1}$ and the one of different constrictions $Q_{b, \max , \varphi}$ as a function of the pump discharge is shown on Figure 6.

The maximum bedload transport capacity of the undisturbed channel can be fitted by a power function:

$Q_{s, \max , 1}=\alpha \cdot Q_{\text {pump }}{ }^{b}+c$

with the constants $a=4.03 \cdot 10^{-5}, b=3.08$ and $c=-4.46 \cdot 10^{-5}\left(R^{2}=0.94\right)$.

The impact of the constriction increases significantly already when the constriction is positioned over the banks without interacting with the main channel bed. Figure 6 indicates that flow constrictions of $0.17 \mathrm{~m}$, which are slightly larger than the base width of the channel of $0.15 \mathrm{~m}$, caused already a drop on the bedload transport capacity. This is due to a modest but present backwater effect which reduces the bedload transport capacity linked to the reduction of the flow velocity 


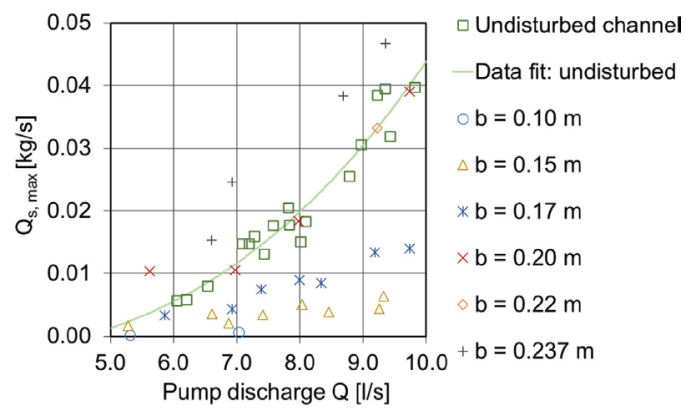

Figure 6. Maximum bedload transport capacity as a function of pump discharges for the undisturbed channel and with constrictions.

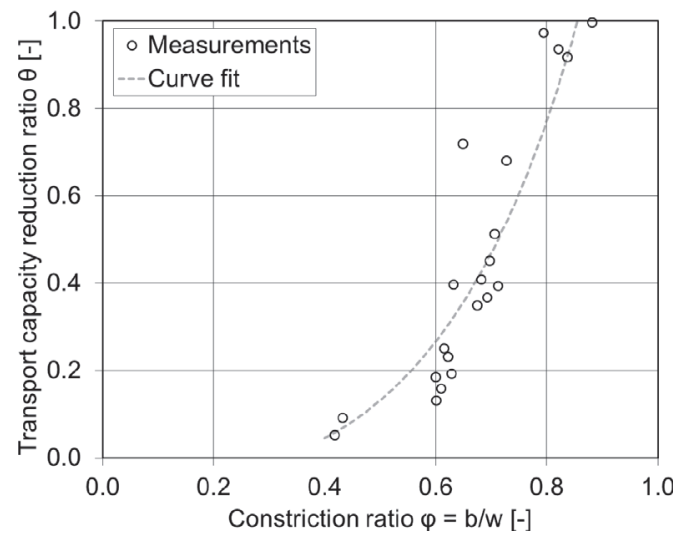

Figure 7. Illustration of the decrease of the bedload transport capacity by means of the transport capacity reduction ratio $\theta$ as function of the constriction ratio $\varphi$.

upstream of the constriction. Lateral constrictions over the river banks do not cause significant backwater as long as the flow conveyed within the base width is not much influenced. However, the flow conditions which lead to the drop of the bedload transport capacity still need to be investigated.

\subsection{Impact of lateral constrictions}

The influence of lateral flow constrictions on the bedload transport capacity is illustrated in Figure 7 by means of the constriction ratio $\varphi$ and the above introduced bedload transport reduction ratio $\theta$. The potential bedload transport capacity of the undisturbed channel is computed based on measurement which are fitted by the exponential function stated in equation (3).

The empirical points corresponding to the relationship between $\theta$ and $\varphi$ can be fitted to a power function with a good correlation coefficient of
$R^{2}=0.92$, which is represented in Figure 7 by the dashed line:

$\vartheta=a_{*} \cdot \exp \left(\varphi^{b_{*}}-c_{*}\right)-d_{*}$

where $a_{*}=13.0, b_{*}=2.77, c_{*}=2.43$ and $d_{*}=1.2$.

In line with the theory, the impact of the constriction vanishes when the constriction ratio $\varphi$ approaches unity. However, the experiments show that the constriction has no significant influence for values of $\varphi>\sim 0.9$. With decreasing constriction ratio $\varphi$, the bedload transport capacity reduces exponentially and for values of $\varphi<\sim 1 / 3$, it is not possible to convey sediment through the constriction.

\section{CONCLUSIONS}

The functional requirements for the design and construction of open check dams does not only aim at retaining, but also at transferring sediments compatible with the transport capacity of the downstream reaches without endangering neighboring infrastructures. The herein studied relationship between river discharges, bedload transport capacity and the constriction ratio can help to design open check dams in a fashion that they are sufficiently wide for sediment transfer up to small floods and that they block sediment in case of important floods. The experiments have shown that a reduction of the flow width to less than $1 / 3$ of the actual mean channel width (in equilibrium conditions) does not allow for the conveyance of bedload. In this case, the downstream channel bed may be subjected to incision.

The used grain mixture has a minimum size of about $1 / 40$ of the channel base width. Therefore, it is possible that grains which are smaller than $1 / 40$ of the river base width (about $3 \mathrm{~mm}$ in the model) can still pass the constriction.

These results still need to be linked with the channel hydraulics and the resistance which is imposed by the lateral constriction. A key issue will be the hydraulic description of the flow conditions leading to the drop of the bedload transport capacity of the channel. The experimental study needs to be extended by the impact of the variation of the channel slope and by the impact of top flow constrictions, i.e. to analyze open check dams with a closed crest.

\section{ACKNOWLEDGEMENTS}

This research is funded by the Swiss Federal Office for the Environment (FOEN). 


\section{REFERENCES}

Armanini, A. \& Larcher, M. 2001. Rational criterion for designing opening of slit-check dam. Journal of Hydraulic Engineering 127(2): 94-104.

Hunziker, R. 2012. Erfahrungen mit der Aufweitung von Fließgewässern in der Schweiz (German: Experiences with river widening in Switzerland). Österreichische Wasser-und Abfallwirtschaft 64: 379-388, doi:10.1007/ s00506-012-0010-1.

Kondolf, G.M. 1997. Hungry Water: Effects of Dams and Gravel Mining on River Channels. Environmental Management 21(4): 533-551.

Piton, G., Recking, A. 2015. Design of sediment traps with open check dams: a review, part I: hydraulic and deposition processes. Journal of Hydraulic Engineering 8: 1-16, doi:10.1061/(ASCE)HY.19 43-7900.0001048.
Schwindt, S., Franca, M.J. \& Schleiss, A.J. 2015. Experimental evaluation of the discharge capacity of flow constrictions by check dams in mountain rivers. 36th IAHR World Congress. The Hague.

Smart, G.M. \& Jaeggi, M.N.R. 1983. Sedimenttransport in steilen Gerinnen. Mitteilungen der Versuchsanstalt für Wasserbau, Hydrologie und Glaziologie der ETH Zürich 64. Zürich.

Syvitski, J.P.M., Overeem, I., Brakenridge, G.R. \& Hannon, M. 2012. Floods, floodplains, delta plains-A satellite imaging approach. Sedimentary Geology 267-268: 1-14.

Williams, G.P. \& Wolman, M.G. 1984. Downstream effects of dams on alluvial rivers. US Geological Survey Professional Paper 1286: 83p. 